\title{
Debunking the Myths: Mental Illness and Mass Shootings
}

\author{
Brian Van Brunt, EdD and Lisa Pescara-Kovach, PhD
}

\begin{abstract}
There is a pervasive assumption that mental illness equates to dangerousness and violence as it relates to mass shootings. The researchers examine the assumption and present a comprehensive literature review of how issues of mental illness impact violence and dangerousness. Many risk factors for violence are associated with mental health conditions, but they also occur in the absence of a diagnosis. A range of issues will be explored, including the unpredictability of bipolar disorder and schizophrenia, stress from mental health problems inhibiting emotional stability, and past inpatient hospitalizations for suicide attempts as they impact likelihood of committing targeted violence. Risk mitigation strategies will be presented following a review of the literature.
\end{abstract}

Keywords: mental health, dangerousness, mental illness violence, predatory violence

\section{The Nature of the Problem}

$\mathbf{T}$ HE MEDIA AND PUBLIC OPINION often portray mental illness as a main cause of targeted or mass shooting violence. However, the presence of a mental health diagnosis should not be overemphasized in a violence risk or threat assessment. It is one of many risk factors related to targeted violence (Engel 1977; Langman 2017). A more accurate model sees these risk factors as a combinatorial effect of mental healthassociated factors and other biopsychosocial risk factors. Overly simplistic portrayals of those struggling with mental health issues as directly causing targeted violence are unfounded and insulting to those with mental illness. These individuals are not more dangerous than the general population. Perhaps the larger concern is the overreliance from the media, public, community, and threat assessment professionals who stress the presence of a mental health diagnosis as explanatory for targeted violence and mass shootings. While the idea that those with mental health problems would seem more likely to commit such heinous acts seem to logically fit, this is a shortsighted analysis of a shooter's motives.

When assessing the risk for violence, professionals in law enforcement, psychology, criminology, and behavioral intervention/threat assessment should lean on the detailed research related to risk, protective, and mobilization factors. While these include some mental health conditions such as depression and substance use disorder in addition to hopelessness, paranoia, delusions, and suicidality, they make up a small percentage of the overall risk factors related to violence. While it is an important subset, one must not overstate the role of mental illness in assessing the likelihood of an individual perpetrating an act of targeted violence or a mass shooting.

This tendency to overstate mental illness as a causal factor is exacerbated when the media and the court of public opinion present sensationalized and unrelenting depictions of the attack where the attacker's mental illness is often given as a central reason. This is particularly concerning, given attackers often have a desire for attention or fame as a motivation for an attack (Bushman 2017; Lankford 2018). When experiencing these black swan events (Taleb 2007), it is common for the public to search for a simple explanation and solution to a complex problem. A better approach debunks these myths related to mental illness, focuses on responsible media reporting to avoid incomplete or erroneous conclusions, and seeks to educate the general population, media, community, law enforcement officers, psychological services, and violence risk/threat assessment professionals about targeted, predatory, and instrumental violence that fuel mass shootings.

It is worth noting that this creation and consumption of these portrayals is a symbiotic process and bringing about change requires adjustments to the production of the material as well as the desire to consume on the part of the public. When the public is presented with vivid imagery and concrete pictures of a disaster, this can crowd out other thoughts (Sunstein 2003) and "These acts can create fear that greatly outruns the discounted probability of harm" (p. 128). Approaching this problem from an educational standpoint to better increase public awareness of this phenomena is an important piece of addressing this dilemma.

Center for Education in Targeted Violence and Suicide, University of Toledo, Toledo, Ohio. 


\section{The Sky Is Falling}

Media portrayals of mental illness rarely cast a positive light on those who are dealing with mental health concerns. Schreiber's story of Sybil, Stephen King's portrayal of Carrie, and Alfred Hitchcock's Psycho present a fairly negative view of mentally ill parents inflicting horror after horror on their children. Each is an exaggerated depiction of symptom manifestation that has the potential to mislead the public, increase stigma, and foster contagion. For example, in the decades before the release of Sybil as a nonfiction book, diagnoses of Multiple Personality Disorder were in the hundreds. Following the book's release, thousands of individuals came forward claiming multiple personalities and the numbers only increased once the film was introduced. In 2013, the 60-min episode, Imminent Danger, explored schizophrenia and violence, providing an example of the media's portrayal of mental illness and dangerousness. Watson (2014) describes the show as, "... quite misleading and frankly stigmatizing to those who suffer with mental disorders, especially those diagnosed with schizophrenia" (p 51). Serper and Bergman (2013) support this idea, given that $90 \%$ of persons with mental illness have no history of violence.

Subsequent to the 2014 incident at Sandy Hook Elementary School, there were reports indicating that the perpetrator suffered from Asperger's Syndrome (now defined as an Autism Spectrum Disorder or ASD), a neurodevelopmental disorder, which has primary diagnostic criteria of "persistent difficulties in the social use of verbal and nonverbal communication..." (Reynolds and Kamphaus 2013, p. 1). The condition manifests itself early in development as difficulty in social communication, an inability to pragmatically modify language based on the setting, difficulties engaging in turn-taking and other conversation etiquette, difficulty comprehending figurative speech, and using metaphors and symbols in place of proper verbiage. The aforementioned struggles are disruptive to the individual's ability to maintain friendships, engage socially, and succeed academically. These traits can occur within the ASD diagnosis as well as the general population. The issue is not the mental health disorder, but rather how these individual risk factors manifest and interact with other biosocial factors. There was no mention of these as separate risk factors apart from mental illness in an article published in The Washington Post, May 2014, was headlined Study: 'Significant' Link Between Mass Murder and Autism, Brain Injury. The practice of "headline-grabbing" is commonplace in the media and often results in people only reading an article's headline. This particular article reviewed the findings of research conducted by Allely, Minnis, Thompson, Wilson, and Gillberg (2014). They state:

Our findings tentatively indicate that these extreme forms of violence may be a result of a highly complex interaction of biological, psychological and sociological factors and that, potentially, a significant proportion of mass or serial killers may have had neurodevelopmental disorders such as ASD or head injury. (p. 1)

Of significance is the word "may" within the abstract, in addition to the authors (Allely et al.) listing an interaction of biological, psychological, and sociological factors exam- ined. According to McCoy (2014), "Despite the patterns that emerged in the study, researchers cautioned against sweeping conclusions. Neurodevelopmental disorders, they said, do not portend mass murder" (p. 3). Engel (1977) stressed the significance of abandoning a singular biomedical model in favor of a biopsychosocial approach to diagnosis and treatment that takes into account "the patient, the social context in which he lives, and the complementary system devised by society to deal with the disruptive effects of illness" (Engel 1977, p. 132). Although Engel spoke of the biopsychosocial influences with regard to nonpsychiatric illness, Langman (2017) presents a strong case for a biopsychosocial approach to school shooters.

Langman's review of 60 past school shooter profiles supports Engel's perspective that mental illness is not the sole contributing factor. In Langman's review, biological influences on an individual took the form of appearancerelated factors (e.g., facial anomaly; small stature). Psychological influences such as narcissism, lack of empathy, inconsistent caregivers, and other family trauma were implicated, as were such social influences such as access to weapons, demands from parents, failed military aspirations, and sibling rivalry. The 2018 Marjory Stoneman Douglas shooter was bullied for having large ears. He recently experienced the loss of his mother and, as such, had to take residence with a classmate's family. In terms of his own family dynamics, his brother has since come forward expressing remorse for mistreating the shooter in the months before the incident. Although not one of the cases is reviewed in Langman's research, this is further support for the accuracy of the biopsychocial approach.

A sample of public mass shootings or serial murders have led to the public, rather than a clinician, diagnosing the perpetrator with some form of Severe Mental Illness (SMI). Common media diagnoses that follow a public mass shooting are antisocial personal personality disorder, schizoid personality disorder, schizophrenia, ASD, ADHD, and depression. Perpetrators of Virginia Tech, Sandy Hook, Columbine, Marjory Stoneman Douglas, and other public mass shootings have been diagnosed with one or all of the above through media headlines and articles (Sandoval and Siemaszko 2013; Van Brunt 2012).

The challenge before us is recognizing sensationalized media portrayals and noting that single case examples are not sufficient enough to accept the generalization that those with mental illness are at a higher risk to commit targeted or mass violence. While some researchers echo the sentiments of the media, others support findings that those with professionally diagnosed mental illness are more likely to be victims rather than perpetrators of crime (Desmarais et al. 2014; Teplin et al. 2005). As stated by Brand (in Flatow, 2011), "They're media portrayals. No single person's story, even if it's accurately portrayed in a popular press book, generalizes to a whole group of patients." In fact, Swanson states, "If we were able to magically cure schizophrenia, bipolar disorder and major depression, that would be wonderful, but overall violence would go down by only about 4 percent" (Swanson, in Beckett, 2014, p. 1).

While there is evidence to support an increased risk of violence in some mentally ill individuals (Choe et al. 2008; Eronen et al. 1998; Friedman and Michels 2013; Harvard Medical School 2011; Rihmer et al. 2010), this needs to be seen in the context of dozens of additional risk factors and 
with an awareness that mental illness alone does not increase the risk for targeted violence or mass shootings. Many of these factors such as poor stress tolerance, impulse control problems, substance abuse, hopelessness, desperation, and social isolation also occur with those without mental illness diagnoses. The media does a disservice to the public when the presence of mental illness is empathized over other risk factors. When people are scared or ignorant about a cause of violence, they show a disproportionate fear and turn to the most available narrative to explain why the violence occurred. This drives far more fear and attention that would be warranted by numbers (Sunstein 2003).

\section{The Diversity of Mental IIIness}

While there are differences in terms of violence risk across various mental illnesses, people with mental illness are more likely to be the victim of a violent crime than they would be to commit such a crime (Choe et al. 2008; Rodway et al. 2014). In some cases, people with mental illness are up to 11 times more likely to have experienced recent violence when compared with the general population (Khalifeh and Dean 2010). While this victimization does not preclude the individuals with mental illness from engaging in targeted violence, it would be helpful to have the media make this point in the fuller context of the debate as well as encouraging researchers to further explore the role of victimization and perceived victimization as a critical risk factor as Lankford (2018) explores to an extent in his recent research.

More serious mental illness, such as substance use disorders, schizophrenia, and bipolar disorders 1 and 2, presents an increased risk for violence when compared with other illnesses (Rihmer et al. 2010). Overall, individuals with these disorders are two to three times more likely to be assaultive (Friedman and Michels 2013). Major depression has the potential to pose a risk of manifesting with suicide and hopelessness, risk factors identified in the threat assessment literature (Chen 2009; Van Brunt 2015). Substance use disorder, which is classified as a mental illness in the DSM-V, produces intoxication and inebriation associated with lowering impulse control and reducing critical thought. In the spectrum of mental illnesses, the misuse of alcohol and drugs contributes the most to violent behavior followed by substance abuse and depression contributing to murdersuicides (Eliason 2009). When looking specifically at those who abuse alcohol or drugs but have no other mental disorder, Friedman and Michels found these individuals are "...nearly seven times as likely as those without substance abuse to commit violent acts" (Friedman and Michels 2013, page 455). It would be reasonable to assume the comorbidity of substance abuse with schizophrenia and bipolar would likely increase this risk. Likewise, some substances create increases in feelings of isolation, paranoia, irritability, aggression, and violence.

In addition to understanding the potential ways a mental health disorder may impact an individual's ability to function, each mental illness should be seen on a spectrum of severity. Many with complex cases of mental illness, such as schizophrenia or major depression, have adequate treatment and medication that help keep symptoms under control. So, in addition to understanding the type of mental illness and potential impact on increasing violence risk, it is also essential to rate the severity of the symptoms. Those that experience higher degrees of symptom severity will require more invasive, costly, and frequent management. Reducing the stigma related to seeking mental health treatment and improving timely access to helpful resources are essential pieces of any violence prevention framework. Untreated mental health symptoms present an additional risk factor for those conducting violence risk and mental health assessments (ATAP 2006; Dunkle et al. 2008; Harvard Medical School 2011; Van Brunt 2012, 2015).

Mental illness, including substance and drug use, should be seen as some of the many risk factors included in the overall violence risk and threat assessment process. Targeted violence is a goal-directed behavior that often occurs along with substance dependence and other mental health symptoms. Issues related to loneliness, marginalization, hopelessness, suicide, and substance dependence are important risk factors to explore when conducting a violence risk or threat assessment (Meloy et al. 2011; Turner and Gelles 2003; United States Post Office 2007; Van Brunt 2015; Van Brunt et al. 2017). Those societal factors that exacerbate mental illness, such as bullying, isolation, socioeconomic stress, a lack of empathy and understanding, funding deficits related to timely access to quality mental healthcare, and the fragmentation of social support structures and community, also increase the risk of targeted violence and mass shootings.

\section{Black Swan Events}

A black swan event, first defined by Nassim Nicholas Taleb (2007), speaks to the extreme impact of high-profile, hard-to-predict, outlier incidents and society's tendency to make overly simplistic explanations when attributing cause or meaning. When the media portrays these events in a sensational or unrelenting manner, viewers, including those in the fields of criminal justice/law enforcement, psychology, behavioral intervention, and threat assessment might be led to inaccurate conclusions. In this study, there are three examples of black swan events that drew the media and public opinion toward the idea that schizophrenics are dangerous.

- Northern Illinois Shooting (2/14/2008): Steven Kazmierczak injured over 21 students and killed five before committing suicide at Northern Illinois University. There had been reports of his struggles with mental illness, suicide attempts, and being bullied in high school (Vann 2008). He had been diagnosed with schizoaffective disorder as a teenager.

- Safeway shooting in Tucson Arizona (1/8/2011): Jared Loughner shot Gabrielle Giffords in a Safeway parking lot. He was diagnosed with paranoid schizophrenia shortly after the incident, which claimed the life of six, including 9-year-old bystander, Christina-Taylor Green. In the years before the shooting, Loughner went from a quiet saxophone player to a young man who felt the government was trying to control him (Cloud 2011). He often spoke in disjoined, illogical sentences and could not follow instructions.

- Century 16 Theatre Attack (8/20/2012): The perpetrator of the Aurora, Colorado shooting went from being a coherent college student to murdering 12 and 
injuring 70. When interviewed by a court-appointed psychiatrist, Holmes stated, "I guess my mind was kind of falling apart" (Strassman 2015). Holmes struggled with anxiety and psychosis and was prescribed medication while at school.

When we hear the horror stories of mentally ill individuals committing horrific attacks, this can dovetail with our personal experiences where mentally ill individuals have behaved dangerously. It is difficult for those in criminal justice, psychology, behavioral intervention and threat assessment teams, and law enforcement to pause and appreciate that while the delusions, hopelessness, and paranoia may have contributed to the overall risk, mental illness is not among the main factors that moved any of these killers forward with their attacks. There are hundreds of thousands of people with schizophrenia who do not escalate to a mass shooting.

As horrible as these single incidents are, it is important to understand that a few cases do not imply a larger cause and effect phenomenon. Yet, the majority of us have read speculative reports presented as fact that imply a connection between mass murder and ADHD (e.g., Richard Ramirez, Nikolas Cruz, Eric Harris, Dylan Klebold) or Asperger's syndrome (e.g., Adam Lanza, James Holmes, Anders Brievik). Knoll and Annas (2016) write:

Thus, the assumption that all persons with mental illness are a "high-risk" population relative to violence generally and gun violence in particular lacks supportive evidence. The likelihood of error and oversimplification is substantial when mental illness is considered.... (p. 90)

When examining mass casualty shooting events, it is common to see a single, horrific case used to make a correlation that may or may not be true. The process we should apply, instead, involves a careful understanding of the risk factors present in a given situation and take protective steps to ensure the fitness of individuals.

\section{Mental IIIness Versus Violence and Threat Risk Factors}

One cannot deny that many instances of targeted and mass casualty gun violence involve an attacker with some form of mental illness. Nevertheless, the mental diagnosis itself should not be our focus here, rather we should assess the additional risk factors for violence. These risk factors have been summarized and written about extensively (Calhoun and Weston 2009; Lankford 2018, Langman 2009; 2015; Mohandie 2014; Meloy et al. 2011; Monahan and Steadman 2001; Monahan 1981; Turner and Gelles 2003; Van Brunt 2012, 2015) and include research from the Department of Education, the U.S. Post Office, Federal Bureau of investigation (FBI), Secret Service, and Homeland Security. These factors include: the presence of a direct threat, hopelessness, weapon acquisition, injustice collecting, a fixation and focus on target, costuming and preattack planning, a movement to action, a time imperative, poor empathy, or a catalyst event such as loss of family member or loved one (Meloy et al. 2011; Van Brunt 2012, 2015). An additional risk factor centers on individuals with a history of drug or substance use that has been connected to inappropriate ideation or behavior. Substances of enhanced concern are methamphetamines or amphetamines, cocaine, or alcohol (ATAP 2006; O'Toole and Bowman 2011; Turner and Gelles 2003; United States Postal Service 2007; Van Brunt 2015). As mentioned previously, some substances can induce symptoms of mental illness such as mania, psychosis, irritability, or impulse control problems.

An individual diagnosed with recurrent major depression is not necessarily a cause for alarm when looking at violence. Instead, threat and violence risk professionals should determine if that person is isolated, hopeless about their future, and/or in constant emotional pain. While these symptoms may overlap with mental illness, they all also occur outside of a mental health diagnosis (American Psychiatric Association, 2013). As stated by Schimelfening (2016), "It's only in rare instances when certain risk factors-such as depression, substance abuse, the presence of another mental illness, domestic violence, bullying, etc.-come together in a certain way that a vulnerable person starts to feel as if he has no other options but to resort to violence" (p. 1).

The presence of these factors could create a vulnerability and escalation toward violence. For example, the death of a parent presents children with threats to their stability, consistency, and safety. This loss seems to be a contributing factor in the Parkland school shooting on 2/14/2018, where the attacker's adoptive parents both passed away, his father several years ago from a heart attack and his mother in November of 2017 (Kennedy 2018).

While some symptoms are common to both mental health diagnoses and the risk factors for violence, we should be more interested in component behaviors, emotions, and thoughts rather than the diagnostic code. Those conducting violence risk assessments should carefully assess the level of hopelessness and desperation as they relate to future action and harm to self as well as others. Suicidality, or as Lankford describes the concepts as "life indifference," becomes a more concerning factor to assess (Lankford 2018). Retrospective research by the U.S. Secret Service on school shooters from 1974 to 2000 found that at least $78 \%$ had experienced suicidal thoughts or engaged in suicidal behavior before their attack (Vossekuil et al. 2002).

An individual diagnosed with Asperger's or ASD is not necessarily cause for alarm when looking at violence potential. The risk factors related to violence that overlap with an ASD diagnosis may include: an isolation and disconnection from others, a difficulty forming social connection, feelings of marginalization, and not feeling part of the community. Cho, the killer at Virginia Tech in 2007, displayed many of these social difficulties throughout his life. From the Virginia Tech Review Panel (2007) report:

For all of his 23 years of life, the most frequent observation made by anyone about him was that he had absolutely no social life. During all of his school years he had no real friends. He had no interest in being with others. In fact, he shied away from other people and seemed to prefer his own company to the company of others. His few attempts to reach out to females at college were inappropriate and frightened them. Of note, this isolation or social difficulty is different from shyness, solitude, or a preference for limited social interaction. Isolation usually comes 
from a feeling of separation, difference, teasing, fear, or anxiety. Isolation from the community, rather than a diagnosis of autism or selective mutism, should be the warning sign flagged by threat assessors. Those conducting the violence risk assessment should carefully assess the level of social isolation, marginalization and disconnection as these relate to future action and harm to self and others. (p. N-3)

As stated by Kadin and Statler (2017), social isolation continues to be the keystone and hallmark indicator of propensities for the type of homicidal psychopathy displayed by mass shooters.

Rather than focusing on mental illness as a useful metric to assess violence, Meloy et al. (2011) identify the following warning behaviors to attend to when assessing a potential threat of mass violence: pathway warning behavior, fixation, identification, novel aggression, energy burst, leakage, last resort, and directly communicated threat. A disturbing, veiled threat might also be a warning. O'Toole and Bowman (2011) highlight concerning, threatening, and dangerous behavior as risk elements that indicated the potential for escalating violence in the book Dangerous Instincts rather than focusing on mental illness. Mohandie (2014) had this observation:

Many of the common patterns observed among school violence offenders mirror the commonalities of suicidal individuals as observed by Shneidman (1996): (1) solution- seeking, (2) cessation of consciousness, (3) unbearable psychological pain, (4) frustrated psychological needs, (5) common emotion of hopelessness/helplessness, (6) cognitive state of ambivalence, (7) perceptual state of constriction, (8) common action in escape, (9) common interpersonal act is communication of intent, and (10) consistency of lifelong styles. Violent actions, fantasy, and planning offer a grandiose, omnipotent attitude to counteract feelings of hopelessness and helplessness in homicidal (and sometimes concurrently suicidal) individuals. (p. 128)

Van Brunt et al. (2017) explore the nature of these risk factors as they apply to terrorism and extremist violence. Risk elements include: "hardened point of view, injustice collecting, marginalization and perceived discrimination, connection to extremists, affiliation seeking, indoctrination into polarized religious thinking, cognitive bleakness, personal failures, societal disengagement, justification to violent action, and predisposing characteristics" (p. 84). These are balanced against protective elements that reduce the risk of violence and are summarized here: "social connection, pluralistic inclusivity, nonviolent outlets, social safety, emotional stability, professional/academic engagement, global competence, empathy, resilience, and an awareness of consequences of actions" (p. 87).

Lankford $(2012 ; 2018)$ focuses on a triad of risk factors, including (a) suicidal motives and life indifference, (b) perceived victimization, and (c) desires for attention or fame. He suggests looking for risk factors such as leakage, psychological fixation, planning and preparation, identification with other mass shooters or extremists, acquisition of weapons, experience of financial loss/crisis/legal problem, giving away prized possessions, disconnection from loved ones, or an anticipated crisis they seek to escape.

Violence risk and threat assessments are most effective when they identify the risk factors but do not make assumptions based on a mental health diagnosis. As Polish American philosopher Alfred Korzybski wrote, "The map is not the territory" (Kendig 1990, p. 299). Let us not confuse the presence of the mental illness with the idea that having a mental illness commonly leads to extreme violence. For an individual with mental illness, there may be a risk of violence. But we can only understand this fully when we look at the severity of the mental illness, environmental stressors, and additional risk factors.

\section{Debunking the Myths}

Myth \#1: Most of the violence in our society can be explained by mental illness

It is difficult to watch the news or read the paper without seeing a story related to someone with mental illness committing violent acts. An airline pilot suffering from depression crashes a plane carrying 150 people into the French Alps (Clark and Bilefsky 2015). A veteran with Post Traumatic Stress Disorder (PTSD) goes on a shooting spree at a military base in Texas (Zoroya 2014). A student with Asperger's (now defined as ASD) kills dozens of young children at an elementary school in Connecticut (Sandoval and Siemaszko 2013). It is understandable the media and the public would jump to a conclusion that a mental diagnosis is directly casual to this violence.

As these depictions are upsetting and often sensationalized with weeks and months of media coverage following the incident, the public assumes these violent acts and planned attacks are both on the rise and caused by mental illness. Despite this belief, there are statistically far more people with the same mental health disorders, such as depression, PTSD, or Asperger's who never go on to commit violent acts (Choe et al. 2008; Langman 2009; 2015). Targeted violence and mass shootings are better understood through the lens of multiple risk factors that include mental illness as one of many pieces to the puzzle (Langman 2017).

As previously indicated, these black swan events occur infrequently and as such bring with them an element of unpredictability and terror that leads to the lay population making assumptions about the increase of these attacks. Black swan events are defined as high-profile, hard-topredict, rare events that the public attaches meaning to with the benefit of hindsight (Taleb 2007). Peter Langman (2009, 2015) makes this point when discussing his typology of school shooters as traumatized, psychotic, and psychopathic. While these traits exist, most people who are traumatized, psychotic, and psychopathic do not commit murder.

An example to support this concept would be found in the number of air disasters that occurred in 2014 and 2015-the disappearance of Malaysia Airlines 370 with 239 people on board on March 8th (Macleod et al. 2014), the shooting down of Malaysian Airlines flight 17 with 298 people on board on July 17th, 2014 (Higgins and Clark 2014), and the pilot who crashed the Germanwings Flight 9525 into the mountainside in France killing 150 on March 24th (Clark and Bilefsky 2015). Many people experienced a severe reaction to these news events and made assumptions about the 
safety of air travel. These 687 lost lives drove several month's news cycles.

To offer some perspective, there were 41,149 deaths by suicide in the United States in 2013 (Centers for Disease Control and Prevention 2015). Collectively, the air disasters mentioned previously took the lives of 687 people. There were 682 fatal traffic deaths in the state of Virginia alone in 2013 - out of 32,719 overall fatalities related to traffic accidents in the United States (IIHS 2015). While mental health violence is scary and brings with it an element of the unknown and increased media exposure, the likelihood of this kind of attack is statistically small when compared with issues of car accident and suicide.

When people are scared and their emotions are engaged intensely, their attention becomes focused on the bad outcome itself regardless of whether or not it is likely to reoccur. This "probability neglect" was described by Sunstein in 2003 where the public will demand legal interventions from the government or seek clear answers for the cause. When mental illness is offered up by the media to a population hungry for answers, it follows that the public draws inaccurate conclusions.

\section{Myth \#2: Mental Illness drives individuals to commit mass shootings}

Mass shootings are a specific form of black swan event that have recently been argued to be influenced by mental illness or those on medication (Ross 2013). While it does appear many of those involved in mass shootings have been on psychiatric medications (Roberts 2013), the idea that the mental illness or psychoactive medication directly contributes to the shooting is not supported by the data. There are millions of people taking these medications who never carry out such attacks. Equating mental illness as the central factor leading to mass shootings is not accurate. It comes as a result of people's inability to accurately assess risk, as demonstrated by Kunreauther et al. (2001) who found subjects had little perception of riskiness for risks ranging from 1 in 650, to 1 in 6300, to 1 in 68,000.

In 2012, James Holmes killed 12 and injured dozens of others in a movie theatre in Aurora, Colorado (Jacobo 2017). Before his attack, he mailed a notebook to his psychiatrist that offered a foreshadowing of the attack (La Ganga 2015). The desire to be known and to communicate the motivations and influence the media message is often strong in those who commit mass violence. Holmes was diagnosed with schizotypal personality disorder during the course of the investigation and trial (McKinley 2015). The mental illness is part of the overall risk, however, attributing the personality disorder as casual to the attack is not supported by the data.

Adam Lanza, who shot 20 children and six adults at Sandy Hook Elementary School in December 2012 (Sandoval and Siemaszko 2013), was said to suffer from Asperger's disorder. In the aftermath of the shooting, the question was asked if the Asperger's was the primary contributor to the shooting. While elements of the disorder contributed to Lanza's development of an attack plan, such as the social isolation severely limiting his communication with others and preventing any leakage about the pending attack, the diagnosis itself is not the reason he carried out his attack. The causal inference is wrongly exacerbated when the media speculates that in- dividuals on the spectrum of autism have a higher potential for violence. This speculation is also not supported by the literature (Søndenaa et al. 2014).

In both of these cases, mental illness was one of a multitude of risk factors that likely set the stage for the attack. It would be reasonable to argue that some of these mental health symptoms created a vulnerability aggravating the risk of violence. These risk factors such as hopelessness, social isolation, injustice collecting, and a hardened point of view often overlap with mental health diagnoses giving the impression that mental illness itself is the cause of these attacks. While the leakage in these attacks, the sharing of the attack plan with a third party, may be exacerbated by mental illness, the careful examination of all the component risk factors for mass shooting is more accurate to explore in prevention of violence (Van Brunt 2015).

\section{Myth \#3: Those with bipolar disorder or schizophrenia are particularly dangerous}

Those experiencing active symptoms of schizophrenia or bipolar mania may, in fact, present a higher risk of committing affective violence (Choe et al. 2008; Friedman and Michels 2013; Harvard Medical School 2011; Rihmer et al. 2010). These deficits in impulse control, information processing, focus, empathy, and frustration tolerance, regardless of mental health status, are associated with this more reactive violence. Untreated schizophrenia may include powerful hallucinations and delusions that could cause the individual to lose touch with reality and make questionable, impulsive decisions regarding their safety or hurting for those around them. Likewise, those experiencing an intense manic phase of their bipolar disorder may have racing thoughts and impulsive actions that could put those around them at risk.

As the individual with bipolar disorder or schizophrenia becomes increasingly upset and escalates, they display a pattern of consistent behaviors and observable characteristics. This affective (reactive/impulsive) violence has been outlined by Meloy (2000, 2006), and is an adrenaline-driven process that occurs as part of a biological reaction to aggression leading to the production of adrenaline, an increase in the heart rate, rising body language, and behavior and communication indicators that we can identify and measure (Grossman and Siddle 2000; Hart 1995). Threat and fear drive affective violence-it is the "fight" in "fight or flight." While this type of violence is concerning and there is a higher occurrence when compared with other mental health conditions, it does not the process associated with mass shootings. These are driven by targeted, instrumental or strategic violence characterized by thoughtful planning, harboring of past wrongs, and the development of a plan of attack.

For those with more reactive and affective violence risk, proper symptom management reduces the hallucinations, delusions, impulsive actions, or racing thoughts, allowing the individual to function much like those without the disorder. The caution here is to avoid a myopic focus on the presence of the diagnosis and instead assess how the individual, their treatment providers, and support system ensure medication and treatment compliance. Much in the same way, untreated diabetes or severe pain from a broken leg would impact an individual's ability to attend to daily life 
requirements, once the underlying issues are treated, the individual is once again able to continue living in a normal and appropriate manner.

In the end, an individual with bipolar disorder or schizophrenia necessitates further exploration of their compliance with therapy, medications, social supports, and their history of remaining consistent and in communication with treating professionals about their symptoms. These secondary questions are much more likely to yield accurate information about the risk of the individual behaving in a more reactive and impulsive manner. When assessing the risk for targeted, planned, and strategic attacks, there are more productive and effective risk factors to explore beyond the presence of a mental health diagnosis.

\section{Myth \#4: The stress of mental illness increases the risk of violence}

We all experience stress differently. Some may find the experience of riding a roller coaster or speaking in front a large crowd stressful; others may enjoy riding a roller coaster or find speaking to a crowd invigorating. Daily stressors such as achieving academic or career goals, balancing work stress, and developing and maintaining friendships are experienced more intently by the majority of people with mental illness. Those impacted by mental illness struggle to manage these daily stressors and, as a result, they take an increased emotional toll. To add to the problem, some types of stress are cumulative. Excessive, chronic, and cumulative stress impacts a person's ability to function (Hart 1995; Howard 1999). This can manifest in a lack of washing, having enough to eat, maintaining social friendships, attending work or school, or being available to support a significant other.

A better question to ask about stress would be: "At what point are the individual's coping skills stretched to the point of being unable to function?" While this question could be asked to those with mental illness, it would also be a fair question for those working several jobs or trying to balance a college education and a social life. An individual's mental illness could increase the likelihood of them becoming overwhelmed by stress and therefore be more vulnerable to the concept of lashing out at others in response. When assessing stress as it relates to violence potential, it is better to focus on an indivudal's experience and coping skills/support network rather than a diagnosis. In assessing violence risk, professionals would do well to focus less on the presence of a particular diagnosis, but instead look to how the individual is managing the stress in their lives.

\section{Myth \#5: Once a person is hospitalized for mental illness, the risk for violence skyrockets}

Hospitalization for an individual with a mental illness can occur for a variety of reasons. A hospital stay may be a planned way to adjust medications, provide a brief respite, or seek to reduce overall stress levels. Other times, an inpatient hospitalization may be in reaction to a crisis event, such as a suicide attempt, severe anxiety attack, or losing touch with reality.

Before drawing an inference between a hospitalization and an increase in violence, the context of the hospitalization must be fully explored. If it is voluntary and the individual receives help during their time on the inpatient unit, the hospitalization may very well improve the ability to manage stress and function more effectively upon discharge. Indeed, one would hope that most hospitalizations would leave the person better than they were before being hospitalized. Watson's (2014) research supports this, "Individuals who are diagnosed with 'mental illness,' even when being recently discharged, are 'not statistically more dangerous than people in the communities they were discharged to, and those same patients were no more dangerous even if they had threat/control delusions." (Watson 2014, page 55)

Understanding the situational factors surrounding the hospitalization becomes essential in understanding the potential risk for future violence or impact on the individual's availability to function. Simply drawing a thick line of connection between being hospitalized and an increase in the person's violence risk oversimplifies the complexities at hand. Instead of focusing on hospitalization, a more accurate assessment would consider additional facts. For example, violence is more common in young people, particularly males, who also experience social or personal stress and have an "early exposure" to violence (Harvard Medical School 2011).

\section{Myth \#6: If someone is suicidal or hopeless, they are going to carry out a mass shooting or targeted attack}

This is not true. Suicide attempts may offer an individual with a mental illness a sense of "hitting bottom" and following the attempt, an acute awareness of the illness. Individuals may be more open to seeking services, treatment, and support for their mental illness to get the help they need. The suicide attempt itself may be the call to action that leads to positive, lasting change. In other situations, the suicide attempt is one of many and this chronic behavior has a devastating effect on the individual. With such a wide range of potential impacts following a suicide attempt, looking at the situation in context from a subjective perspective allows a better understanding of how the incident impacts the risk of targeted violence.

Suicide, and the corresponding hopelessness, is a consistent risk factor for targeted violence throughout the threat assessment literature (Calhoun and Weston 2009; Lankford 2018; Langman 2009; 2015; Mohandie 2014; Meloy et al. 2011; Pescara-Kovach and Raleigh 2017; Monahan and Steadman 2001; Monahan 1981; Turner and Gelles 2003; Van Brunt 2012, 2015). Suicide and hopelessness should be highly considered as risk factors for targeted violence, but the assumption that suicidal people are also thinking about killing others or carrying out a mass shooting is over-stated.

\section{How to Mitigate the Risk}

There are a number of ways to mitigate the risk of overattributing mental illness to potential violence or misrepresenting the impact on an individual's ability to function. The following three approaches allow those in law enforcement, criminal justice, psychological services, and behavioral intervention and threat assessment to better assess the risk by attending to risk factors rather than making broad assumptions concerning mental illness and the proclivity to behave in a violent fashion. As indicated in Allely, Minnis, Thompson, Wilson, and Gillberg (2014); Engel 
(1977), Langman (2017), and McCoy (2014), a biopsychosocial lens provides greater likelihood of an accurate risk assessment.

(1) Look at the component risk factors and behavior, not the diagnosis: A theme of this article has been examining the fundamental areas of mental illness that may stand in the way of attending class, working, and functioning socially. Instead of assuming individuals with a certain diagnosis to be necessarily at a higher risk for violence, risk factors that correlate with targeted attacks should be assessed (Langman 2009; 2015; Mohandie 2014; Meloy et al. 2011; Van Brunt 2012, 2015). While single case studies may give the impression that certain disorders such as schizophrenia or bi-polar disorder lead to violence, there are many with such disorders who received proper treatment and care that allows them to function exceptionally well. This is also true for people with depression; the assumption that they will not have the energy to be consistent or emotionally available to complete daily tasks is highly dependent on external factors. Instead of focusing on the diagnostic label, it is vital to assess the severity of the symptoms, past experiences with treatment, and how the individual is managing the stress in their life related to the mental illness.

Having a diagnosis does not necessarily make someone prone to violence. Similarly, just being prescribed and taking medication does not equal a higher risk for dangerousness. Research shows that "the more psychiatric medications someone is given, the more someone becomes vulnerable to relapse, disability, psychosis, and violence" (Watson 2014, page 56). One partial reason why uncharacteristic acts of violence are seen in patients is related to an unregulated system combined with sudden termination of psychiatric medication. (Watson 2014).

(2) Understand an individual's stress tolerance and management: We all experience stress differently. For some of us, losing a pair of car keys or iPhone may be enough to spin an otherwise peaceful week into disarray. For others, balancing two jobs, attending school, and raising four children while managing the mental health symptoms of anxiety or an eating disorder may simply be par for the course. To assess the risk of dangerousness or the potential for an impulsive or violent reaction, it is vital to first gain an understanding of how the individual manages stress in their life. Research suggests a movement away from biomedical model (Engel 1977) and instead adopting a more biopsychosocial model when understanding the risk for targeted mass shootings (Langman 2017).

Mental illness can certainly have an exacerbating effect on the overall stress a person experiences and thus have a negative impact on an individual's emotional availability, willingness to empathize, or express compassion. With accumulation of such stressors, individuals may be more vulnerable to violent actions (Van Brunt 2015). However, it is just as likely that an individual with a mental illness may have quality $24 / 7$ access to support to keep their stress better managed, allowing them to react in a healthy way. In the end, this must be assessed subjectively and contextually given the environment, supports, and stressors. One should not assume an increase in stress necessarily leads to a failure to cope for someone with mental illness. Many with mental illness are very familiar with stress and have extensive resources and supports they may access during times of heightened stress.

(3) Risk assessment is about identifying triggers and assessing support: When assessing risk in a system, it is not sufficient to identify the factors that may make a situation worse (Hart and Logan 2011; Hart et al. 2011). While an understanding of potential "hot spots" or triggers, such as losing a job, an increase in symptoms of depression, or hearing voices should be identified as events that increase risk, a more accurate risk assessment also evaluates supports and the level of resiliency an individual has in their life that may help the situation improve. While rain may be a negative stressor, it is less so for the individual who has an umbrella. While an increase in manic or impulsive decision-making behavior should be an area of potential risk, it is less so for an individual who can lean on their therapist, has a social support group, and experience managing these symptoms. Assessing risk should both identify how to reduce the negative or trigger events in a person's life as well as looking at the presence of mitigating factors such as peers, family, treatment access, social supports, and past success managing his or her illness.

\section{Conclusion}

Despite what news media, popular movies, and TV shows depict, mental illness is rarely associated with increased dangerousness and never assumed as a cause of violence by those who study this field. Having a mental illness does not constitute a dangerous individual. Instead, we should better assess the threat and violence risk factors along with a person's behavior, treatment compliance, social, peer support, resiliency to stress, and access to crisis services. While those with substance use/abuse, bipolar, and schizophrenia may be at a slightly higher risk for violence, the risk still remains much lower than the general population. Many who live with mental illness actively seek therapy, medication for their illness, and lean on an impressive structure of social, family, and peer support. Those in law enforcement, criminal justice, psychological services, and behavioral intervention and threat assessment are trained and encouraged to focus on a wide variety of contributing factors that may indicate violence as opposed to narrowing the focus on a mental health diagnosis.

By extrapolation, when assessing individuals for dangerousness, mental health assessments alone are problematic. Psychological and mental health assessments seek to determine a diagnosis, develop a treatment plan, determine if an individual should be involuntarily committed, and create a more detailed biopsychosocial evaluation. These assessments are based on mental health and diagnostic knowledge of the psychologist, social worker, therapist, or other clinical staff member. It is only in rare cases that the person conducting the psychological or mental health assessment brings in violence and threat risk factors. Threat 
and violence risk assessments seek to assess the likelihood of dangerousness, assist with decision making regarding work or school status, give opinions regarding violent recidivism after treatment or incarceration, or to better assist in the mitigation and case management of future violence. These assessments are based on workplace violence risk factors, criminology, and psychological factors that indicate an increased risk to violence potential amidst the context of the direct or indirect threat or presenting concern.

Mental health factors make up a small percentage of the overall risk factors related to violence risk. While important, one must not overemphasize these factors or underplay the additional violence risk factors. Mental health factors include depression, suicidality, psychosis and delusions, or substance use disorders. Violence risk factors include the presence of a direct threat and disturbing veiled threat, fixation and focus on target, action and time imperative, lack of empathy, social isolation, injustice collecting, marginalization, fantasy rehearsal, leakage, weapons access, hardened point of view, and feelings of persecution. When preventing violence, the interplay between mental health and risk factors should be the preferred approach, rather than focusing solely on whether or not an individual has a mental illness. Further research would be useful to examine how mass shooters with a clinical diagnosis are different from the majority of those nonviolent individuals with a clinical diagnosis. Furthermore, it would be useful to explore the difference between mass shooters without a diagnosis and nonviolent individuals with a mental illness.

Mental illness is implicated in far too many mass shootings. Of great significance to stigma and proliferation of myths related to mental illness and violence is misinformation published in high volume for the days, weeks, and months following a mass shooting (Pescara-Kovach and Raleigh 2017). Responsible media coverage should include accurate risk factors while actively dispelling myths. Rather than sensationalizing each incident with a detailed minuteby-minute disturbing account of a mass shooter's attack, electronic and tangible media outlets should work toward providing information on the need for and process of risk and threat assessment, including how to report behaviors of concern. Factual information could drastically lower false beliefs while increasing thwarted plots. As Sunstein (2003) writes related to terrorism and the public's tendency to act from a position of probability neglect, "the best response is information and education" (p. 133).

\section{Author Disclosure Statement}

No competing financial interests exist.

\section{References}

Allely CS, Minnis H, Thompson L, Wilson P, Gillberg C. (2014). Neurodevelopmental and psychosocial risk factors in serial killers and mass murderers. Aggression Violent Behav, 9, 288301.

American Psychiatric Association. (2013). Diagnostic and Statistical Manual of Mental Disorders (5th edition.). (American Psychiatric Association, Washington, DC).

Association of Threat Assessment Professionals (ATAP). (2006). Risk Assessment Guideline Elements for Violence (RAGE-V):
Considerations for Assessing the Risk of Future Violent Behavior. (ATAP, Sacramento, CA).

Beckett L. (2014). Interview with Dr Jeffrey Swanson, Myth vs. Fact: Violence and Mental Health. (Pro Publica, New York, NY).

Bushman B. (2017). Narcissism, fame-seeking, and mass shootings. Am Behav Sci. [Epub ahead of print]; DOI:10.1177/0002764217739660.

Calhoun F, Weston S. (2009). Threat Assessment and Management Strategies: Identifying the Howlers and Hunters. (CRC Press, Boca Raton, FL).

Centers for Disease Control and Prevention. (2015). Understanding suicide fact sheet. Retrieved from www.cdc.gov/violenceprevention/ pdf/suicide_factsheet-a.pdf (accessed June 14, 2015).

Chen P. (2009). Jiverly Wong's father: What prompted mass killing in Binghamton remains a mystery. The Post Standard, April 13, 2009. Retrieved from www.syracuse.com/news/index.ssf/2009/04/jiverly wongs_father_our_son_w.html (accessed August 4, 2015).

Choe J, Teplin L, Abram K. (2008). Perpetration of violence, violent victimization, and severe mental illness: Balancing public health concerns. Psychiatr Serv. 59, 153-164.

Clark N, Bilefsky D. (2015). "Germanwings Pilot Was Locked Out of Cockpit Before Crash in France". The New York Times.

Cloud J. (2011). The Troubled Life of Jared Loughner. Time Magazine. Retrieved from http://content.time.com/time/magazine/article/0,9171, 2042358,00.html (accessed September 4, 2018).

Desmarais SL,Van Dorn RA, Johnson KL, et al. (2014). Community Violence Perpetration and Victimization Among Adults With Mental Illnesses. Am J Public Health. 104, 2342-2349.

Dunkle JH, Silverstein ZB, Warner SL. (2008). Managing Violent and other Troubling Students: The role of threat assessment teams on campus. J Coll Univ Law. 34, 3.

Engel G. (1977). The need for a new medical model: A challenge for biomedicine. Am Assoc Adv Sci. 196, 129-136.

Eronen M, Angermeyer M, Schulze B. (1998). The psychiatric epidemiology of violent behaviour. Soc Psychiatry Psychiatr Epidemiol. 33, S13-S23.

Flatow I. (Host). (2011, October 21). Exploring Multiple Personalities in 'Sybil Exposed [Radio broadcast episode].

Friedman R, Michels R. (2013). How Should the Psychiatric Profession Respond to the Recent Mass Killings? Am J Psychiatry. 170, 455-458.

Grossman D, Siddle B. (2000). Psychological effects of combat. In Encyclopedia of Violence, Peace and Conflict. L. Curtis \& J. Turpin, eds. (Academic Press, New York).

Hart A. (1995). Adrenaline and Stress, the Exciting New Breakthrough that Helps You Overcome Stress Damage. (Thomas Nelson Publishers, Nashville, TN).

Hart S, Logan C. (2011). Formulation of violence risk used evidencebased assessment: The structured professional judgment approach. In Forensic Case Formulation. P. Sturmey \& M. McMurran, eds. (Wiley-Blackwell, Chichester, England). pp. 83-106.

Hart S, Sturmey P, Logan C, McMuran M. (2011). Forensic case formulation. Int J Forensic Ment Health. 3131, 118-126.

Harvard Medical School. (2011). Mental Illness and Violence. Harv Ment Health Lett. 27, 1-3.

Higgins A, Clark N. (2014). Malaysian Jet Over Ukraine Was Downed by 'High- Energy Objects,' Dutch Investigators Say. The New York Times.

Howard P. (1999). The Owner's Manual for the Brain: Everyday Applications from Mind- Brain Research (2nd edition.). (Bard Press, Austin, TX).

IIHS. (2015). Insurance Institute for Highway Safety Highway Loss Data Institute. Retrieved from www.iihs.org/iihs/topics/t/generalstatistics/fatalityfacts/state-by-state-overview/2013 (accessed June 14, 2015) 
Jacobo J. (2017). A look back at the Aurora, Colorado, movie theater shooting 5 years later. Retrieved on September 4, 2018 from https:// abcnews.go.com/US/back-aurora-colorado-movie-theater-shootingyears/story?id=48730066.

Kendig M. (1990). Alfred Jorzybski: Collected Writings, 1920-1950. (Institute of General Semantics, Englewood, NJ).

Kennedy K. (2018). Florida shooting suspect was adopted and both of his parents recently died. Associated Press. Retrieved from www .businessinsider.com/florida-shooting-suspect-nicolas-cruz-troubledfamily-life-disturbed-2018-2 (accessed February 24, 2018).

Khalifeh H, Dean K. (2010). Gender and violence against people with severe mental illness. Int Rev Psychiatry. 22, 535-546.

Knoll JL, IV, Annas GD. (2016). Mass shootings and mental illness. In Gun Violence and Mental Illness. LH Gold, RI Simon, eds. pp. 81104.

Kunreauther H, Novemsky N, Kahnmeman D. (2001). "Making Low Probabilities Useful," J Risk Uncertainty. 23, 103-120.

La Ganga M. (2015). James Holmes' sealed notebook gets mentioned by prosecution, and defense. La Times. Retrieved from www.latimes .com/nation/la-na-james-holmes-notebook-20150428-story.html (accessed June 14, 2015).

Langman P. (2009). Rampage School Shooters: A typology. Aggression Violent Behav. 14, 79-86.

Langman P. (2015). School Shooters: Understanding High School, College, and Adult Perpetrators. (Rowman \& Littlefield, New York).

Langman P. (2017). A bio-psycho-social model of school shooters. J Behav Interv Teams. 5, 27-34.

Lankford A. (2012, December 18). What drives suicidal mass killers. The New York Times. Retrieved from www.nytimes.com/2012/12/ 18/opinion/what-drives-suicidal-mass-killers.html (accessed March 4, 2018).

Lankford A. (2018). Identifying Potential Mass Shooters and Suicide Terrorists with Warning Signs of Suicide, Perceived Victimization, and Desires for Attention or Fame. J Pers Assess. 5, 1-12.

MacLeod C, Winter M, Gray A. (2014). "Beijing-bound flight from Malaysia missing". USA Today. Retrieved from www.usatoday .com/story/news/world/2014/03/07/malaysia-airlines-beijing-flightmissiing/6187779/ (accessed June 14, 2015).

McCoy T. (2014). Study: Significant Statistical Link Between Mass Murder and Autism, Brain Injury. Washington Post. Retrieved from www.washingtonpost.com/news/morning-mix/wp/2014/05/21/studyfinds-significant-portion-of-mass-murderers-and-serial-killers-hadneurological-disorders-including-autism/?utm_term=.dcfcbcf66cf0 (accessed March 5, 2018).

McKinley C. (2015). Aurora Shooting Trial: 10 New Things From 22 Hours of James Holmes Psychiatric Evaluation Interviews. ABC News. Retrieved from http://abcnews.go.com/US/aurora-shootingtrial-10-things-22-hours-james/story? $\mathrm{id}=31540740$ (accessed June 14, 2015).

Meloy J. (2000). Violence Risk and Threat Assessment: A Practical Guide for Mental Health and Criminal Justice Professionals. (Specialized Training Services, San Diego, CA).

Meloy JR. (2006). The empirical basis and forensic application of affective and predatory violence. Aust N Z J Psychiatry. 40, 539-547.

Meloy J, Hoffmann J, Guldimann A, James D. (2011). The role of warning behaviors in threat assessment: An exploration and suggested typology. Behav Sci Law. 30, 256-279.

Mohandie K. (2014). Threat assessment in schools. In The International Handbook of Threat Assessment. JR Meloy \& J Hoffman, eds. (Oxford University Press, New York, NY). pp. 126-147
Monahan J. (1981). Predicting Violent Behavior: An Assessment of Clinical Techniques. (Sage Publications, London).

Monahan J, Steadman H. (2001). Rethinking Risk Assessment-The MacArthur Study of Mental Disorder and Violence. (Oxford University Press, New York).

O'Toole ME, Bowman A. (2011). Dangerous Instincts: How Gut Feelings Betray. (Hudson Street Press, New York, NY).

Pescara-Kovach L, Raleigh MJ. (2017). The Contagion Effect as it Relates to Public Mass Shootings and Suicides. J Behav Interv Teams. 5, 35-45.

Reynolds CR, Kamphaus RW. (2013). BASC Autism Spectrum Disorders. Retrieved from https://images.pearsonclinical.com/images/ assets/basc-3/basc3resources/DSM5_DiagnosticCriteria_AutismSpectrum Disorder.pdf (accessed on September 4, 2018).

Rihmer Z, Gonda X, Rihmer A, Fountoulakis KN. (2010). Suicidal and violent behaviour in mood disorders: A major public health problem. A review for the clinician. Int J Psychiatry Clin Pract. 14, 88-94.

Roberts D. (2013). Every Mass Shooting Shares One Thing In Common \& It's NOT Weapons. Ammoland. Retrieved from www.ammoland.com/2013/04/every-mass-shooting-in-the-last-20years-shares-psychotropic-drugs/\#axzz3d5TAGC00 (accessed June 14, 2015)

Rodway C, Flynn S, While D, et al. (2014). Patients with mental illness as victims of homicide: A national consecutive case series. Lancet Psychiatry. 1, 129-134.

Ross M. (2013). When It Comes to School Shootings, Drugs Aren't the Problem. The Huffington Post. Retrieved from www.huffing tonpost.ca/marvin-ross/antipyschotics-school-shootings_b_2467182 .html (accessed June 14, 2015).

Sandoval E, Siemaszko C. (2013, November 26). Inside Adam Lanza's lair. NY Daily News. Retrieved from www.nydailynews.com/news/ national/newtown-shooter-planned-death-obsessed-columbinearticle1.1528626 (accessed June 14, 2015).

Schimelfening N. (2016). Is Depression Linked to Violence? Whether Mood Disorders are To Blame for Violent Tendencies. Retrieved from www.verywellmind.com/is-depression-linked-to-violence1067393?print (accessed March 4, 2018).

Serper M, Bergman A. (2003). Psychotic Violence: Methods, Motives, Madness. (Psychosocial Press, Madison, CT).

Søndenaa EE, Rasmussen K, Helverschou SB, et al. (2014). Violence and sexual offending behavior in people with autism spectrum disorder who have undergone a psychiatric forensic examination. Psychol Rep. 115, 32-43.

Strassman M. (2015). James Holmes Recalls His State of Mind Before the Shooting. ABC News. Retrieved from www.cbsnews.com/ news/james-holmes-recalls-his-state-of-mind-before-coloradoshooting/ (accessed September 4, 2018).

Sunstein CR. (2003). Terrorism and probability neglect. J Risk Uncertainty. 26, 121-136.

Taleb N. (2007). The Black Swan: The Impact of the Highly Improbable. (Random House and Penguin, New York).

Teplin LA, McClelland GM, Abram KM, Weiner DA. (2005). Crime victimization in adults with severe mental illness: Comparison with the National Crime Victimization Survey. Arch Gen Psychiatry. 62, 911-921.

Turner J, Gelles, M. (2003). Threat Assessment: A Risk Management Approach. (Routledge, New York, NY).

United States Postal Service. (2007). Threat Assessment Team Guide. Retrieved from www.nalc.org/depart/cau/pdf/manuals/Pub\%20108\% 20(2007-Mar).pdf (accessed March 4, 2018). 
Van Brunt B. (2012). Ending campus violence: New approaches to prevention. (Routledge, New York, NY).

Van Brunt B. (2015). Harm to Others: The Assessment and Treatment of Dangerousness. (American Counseling Association, Alexandria, VA).

Van Brunt B, Murphy A, O'Toole M. (2017). An exploration of the risk, protective, and mobilization factors related to violent extremism in college populations. J Violence Gend. 4, 81-101.

Vann D. (2008). Portrait of the school shooter as a young man. Esquire. 150, 114

Virginia Tech Review Panel. (2007). Mass shootings at Virginia Tech: Report of the review panel presented to Governor Kaine, Commonwealth of Virginia.

Vossekuil B, Fein R, Reddy M, et al. (2002). The final report and findings of the Safe School Initiative: Implications for the prevention of school attacks in the United States. (U.S. Secret Service and U.S. Department of Education, Washington, DC).
Watson TT. (2014). Confronting 60 Minutes' "Imminent Danger": The evidence on schizophrenia and psychotropic medications, violence, and forced orders to treat. Ethical Hum Psychol Psychiatry. 16, 51-62.

Zoroya G. (2014). Fort Hood shooter Ivan Lopez had mental problems, saw no combat in Iraq. USAToday. Retrieved from www.usa today.com/story/news/nation/2014/04/02/fort-hood-shooter-hadmental-health-problems/7237489/ (accessed June 14, 2015)

Address correspondence to: Brian Van Brunt, EdD

Center for Education in Targeted Violence and Suicide University of Toledo

Toledo, $\mathrm{OH} 19355$

E-mail: brian@ncherm.org 